\title{
Noise Annoyance Produced by Commercial Vehicles Transit on Rumble Strips
}

\author{
Haron Zaiton, ${ }^{1,}$, Yahya Khairulzan $^{1}$, Darus Nadirah $^{1}$, Mashros Nordiana ${ }^{1}$, Hezmi \\ Muhammad Azril ${ }^{1}$, Abu Samah Rosiah ${ }^{2}$, Abdul Hameed Abdul Mutalif ${ }^{2}$, Norudin Wan \\ Mohammad Asyraf ${ }^{1}$, Abd Halil Muhammad Habab ${ }^{1}$, Jahya Zanariah ${ }^{1}$, and Othman Mohd \\ Hanifi $^{3}$ \\ ${ }^{1}$ Faculty of Civil Engineering, Universiti Teknologi Malaysia, 81310 Johor Bahru, Johor, Malaysia \\ ${ }^{2}$ Pusat Kecemerlangan Kejuruteraan \& Teknologi JKR (CReaTE), Jalan Kemus Simpang Empat, \\ 7800 Alor Gajah Melaka \\ ${ }^{3}$ Faculty of Civil and Environmental Engineering, Universiti Tun Hussein Onn Malaysia, 86400 Batu \\ Pahat, Johor, Malaysia
}

\begin{abstract}
This paper reports on research examining the extent of noise annoyance affecting residents within the vicinity of installation of two types of transverse rumble strips (TRS), namely Middle Overlapped (MO) and Multilayer Overlapping (MLO). In order to assess the noise annoyance in the area, measurements were taken at $7.5 \mathrm{~m}$ from centre of road with TRS installation using single vehicle test to determine the extent of changes of sound level indices and sound spectrum. Two light and two medium weight commercial vehicles were used. Indicators $\mathrm{L}_{\text {Aeq, }} \mathrm{L}_{\mathrm{AFmax}}$, $\mathrm{L}_{\text {AImax }}, \mathrm{L}_{\text {AIeq }}$, and $\mathrm{L}_{\mathrm{ASmax}}$ were used to determine impulsivity that led to noise annoyance. The results showed that, at $30 \mathrm{~km} / \mathrm{h}$, all commercial vehicles considered in this study that transited on MO produced impulsive noise, while only light commercial vehicles caused noise annoyance when they transited on MLO. The research also analysed the extent of lowfrequency noise and found a significant low-frequency component, which indicated that noise annoyance might arise from the hitting of $\mathrm{MO}$ and MLO by the commercial vehicles. For night-time related annoyance, it was suggested that an additional weighting factor could be added to the average A-weighted value during night-time.
\end{abstract}

\section{Introduction}

Rumble strips can be defined as a set of yellow bars painted on the pavement with a specific thickness to alert road users through their colour, sound, and physical vibrations. TRS have a specific sectional profile and they are laid perpendicular to the vehicle's flow. In Malaysia, there are three common types of TRS profiles: Multilayer Overlapping (MLO), Rumbler Raised (RR), and Middle Overlapped (MO) [1, 2]. TRS are used to inform road users that there is a change in the road environment that requires drivers to be more cautious. They are placed at a critical point before reaching a junction, roundabout,

\footnotetext{
*Corresponding author: zaitonharon@utm.my
} 
toll plaza, road hump, and pedestrian crossing. These are the alternatives used to reduce accident rate as they give drivers a warning to slow down.

TRS are mostly utilised as traffic calming measures implemented in the vicinity of schools, business areas, and neighbourhoods [2,3]. Thus, one of the prime issues caused by the existence of TRS is noise annoyance. Night-time noise that causes sleep disturbance is the major source of concern, therefore, some TRS have to be replaced by other traffic calming devices due to the complaints by nearby residents. TRS' physical properties such as profile, thickness, number, and spacing between bar are selected without any proper references to standards or guidelines [4], and purely on the basis of the local traffic engineers' experience. Apart from that, vehicle speed on the road will also affect the level of noise during transit on the TRS. Furthermore, it was found that, as the vehicle speed increased the pass-by noise levels caused by the TRS also increased [1,5]. In addition to that, the vehicle's type and weight also influenced the noise level. Haron et al (2016) found that a $980 \mathrm{~kg}$ compact car caused a significant increase in pass-by noise level when it traversed the TRS and generated a significant impulsive sound that made it more annoying than a continuous noise [1]. According to An et al. [5] in general, the increase in noise was greater at $100 \mathrm{~km} / \mathrm{h}$ than at $40 \mathrm{~km} / \mathrm{h}$ and lower for a sedan than a truck.

Previous research suggested that the typical evaluations of noise annoyance based on the A-weighted equivalent level by the regulatory authorities were inadequate and can lead to incorrect decisions [6]. Annoyance caused by sound in the low-frequency region $(20 \mathrm{~Hz}$ up to $100 \mathrm{~Hz}$ ) cannot be assessed using the A-weighting but rather with the consideration of the C-weighting [7]. Moreover, it was suggested that low-frequency components may increase the adverse effects considerably, pose more detrimental impacts to public health, and become more annoying as claimed by individuals $[8,9]$. Acoustically, noise annoyance is the result of interference with daily activities, feelings, thoughts, sleep, or rest, and may be accompanied by negative emotional responses, such as irritability, distress, exhaustion, a wish to escape the noise and other stress-related symptoms [10].

The current study investigated noise annoyance that arisen due to TRS installation by commercial vehicles with a particular emphasis on low frequency noise content. It focused on commercial vehicles because their percentage on the road is currently about $12 \%$ [11] and represented $10 \%$ of the total sales of vehicles in Malaysia as of March 2017. Furthermore, in traffic noise prediction, commercial vehicles are denoted as light, medium, and heavy vehicles. Therefore, the objectives of this research are to (1) determine the change in sound level indices associated with the installation of two TRS profiles, and (2) analyse noise annoyance objectively through sound level changes and low-frequency content.

\section{Methodology}

\subsection{Measurement of sound level indices and frequency spectrum}

The study focused on the change of sound level indices, impulsivity, and low-frequency content due to the transition of vehicles on the two types of TRS. Two road stretches in the state of Johor installed with MO (located at Skudai, width $=600 \mathrm{~mm}$ ) and MLO (located at Kangkar Pulai, width $=400 \mathrm{~mm}$ ) were selected, with pavement and thermoplastic TRS profile were in good condition and have the same thickness $(3 \mathrm{~mm})$. Profile of both TRS is shown in Figure 1. The commercial vehicles adopted for the tests were 2 light vehicles (LV) (Toyota Hilux, with gross vehicle mass $(\mathrm{GVW}=2780 \mathrm{~kg}), 1$ HiAce van $(\mathrm{GVW}=2600$ $\mathrm{kg}$ ), and 2 medium vehicles (MV) namely a one ton lorry ( GVW $=5000 \mathrm{~kg}$ ) and a 40 seater bus $(\mathrm{GVM}=7700 \mathrm{~kg})$. 
Measurements were carried out at mid-night to avoid disturbance from other noise sources. Also, wind speed and air temperature were below $5 \mathrm{~m} / \mathrm{s}$ and $5^{\circ} \mathrm{c}$ to $40^{\circ} \mathrm{c}$, respectively for data validity [13]. The sound levels were measured using control pass-by (CPB) method in which microphones was placed at a defined distance from the vehicle path at the side of the roadway (Fig. 1). For measurement of noise level due to TS installation, sound level meter Pulsar Type 1 was placed at Point 1 at $7.5 \mathrm{~m}$ from the centre of the vehicle lane at a height of $1.2 \mathrm{~m}$ above the pavement [12]. Measurement for determination of sound level indices and frequency spectrum in this study were carried out separately. The noise indices recorded were $\mathrm{L}_{\mathrm{Aeq}}, \mathrm{L}_{\mathrm{AFmax}}, \mathrm{L}_{\mathrm{ASmax}}, \mathrm{L}_{\mathrm{AImax}}$ and $\mathrm{L}_{\mathrm{AIeqT}}$. The $\mathrm{L}_{\mathrm{Aeq}}$ is the constant noise level that expends the same amount of energy as a fluctuating level over the same time period [12]. $\mathrm{L}_{\mathrm{AFmax}}$ is fast response maximum with the equivalent A-weighted sound pressure level while $\mathrm{L}_{\mathrm{AImax}}$ is maximum A-weighted impulse response. Meanwhile, LAIeqT is the A-weighted impulse sound pressure levels averaged over the same time interval and $\mathrm{L}_{\mathrm{ASmax}}$ is slow response maximum with the equivalent $\mathrm{A}$-weighted sound pressure level. For determination of sound level indices and frequency spectrum, each vehicle was run using speed $30 \mathrm{~km} / \mathrm{h}$ and $50 \mathrm{~km} / \mathrm{h}$ as these speeds are the speed limit imposed on roadway at critical point and in each speed test were repeated 3 times. Vice versa point 2 was used to record the noise level when vehicles were run without TRS with the whole activities were repeated.

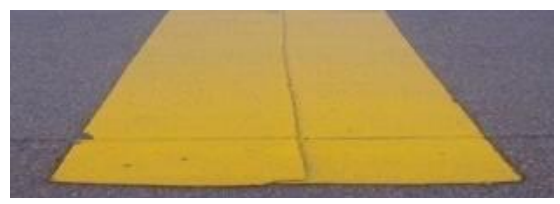

i) MO profile

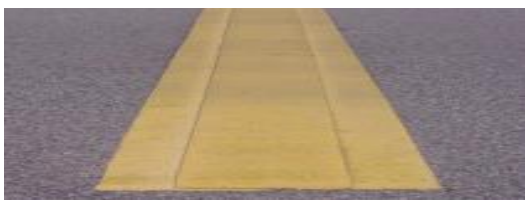

ii) MLO profile

(a) Rumble strips profiles

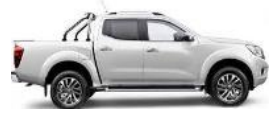

i) Hilux $(2780 \mathrm{~kg})$

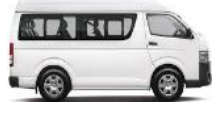

ii)Hiace $(2600 \mathrm{~kg})$

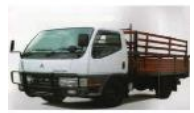

iii)Lorry $(5000 \mathrm{~kg})$

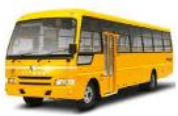

iv)Bus (7700 kg)

(b) Test vehicles types

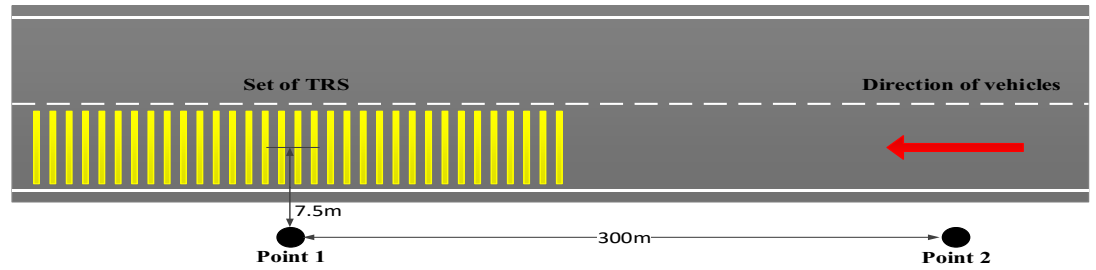

(c) Experimental set up

Fig. 1. Profiles of TRS, test vehicles and measurement layout.

\subsection{Change in sound levels indices}

The change of noise level, $\mathrm{L}_{\text {Aeq }}$ can be directly obtained from the disparities of values between the tests (with and without TRS). A 3-dB change in noise level is considered just discernible; a 5-dB change is clearly discernible; and a 10-dB change louder or softer is perceived as a doubling or halving of volume, respectively [17]. Further, in this study, the significance of impulsivity was determined using several criteria involving recorded noise 
indices as suggested in previous research. In order to objectify the annoyance, the difference in noise indices was compared with the reference value. If any of these reference values is exceeded, it is assumed that the annoyance/complaint is objectively attributable to the TRS source. The reference values of the guideline are shown in Table 1.

Table 1. Impulsive characteristic determination.

\begin{tabular}{|l|c|c|c|c|}
\hline Different in noise indices & $\begin{array}{c}\mathrm{L}_{\mathrm{AFmax}}- \\
\mathrm{L}_{\mathrm{AImax}}\end{array}$ & $\mathrm{L}_{\mathrm{AFmax}}-\mathrm{L}_{\mathrm{Aeq}}$ & $\mathrm{L}_{\mathrm{AIeqT}}-\mathrm{L}_{\mathrm{Aeq}}$ & $\begin{array}{c}\mathrm{L}_{\mathrm{AImax}}- \\
\mathrm{L}_{\mathrm{ASmax}}\end{array}$ \\
\hline References limit (dB (A)) & 2 & 10 & 2 & 6 \\
\hline
\end{tabular}

\subsection{Analysing the Low frequency noise for the annoyance}

Data on frequency spectra were used to calculate $\mathrm{dB}(\mathrm{A})$ and $\mathrm{dB}(\mathrm{C})$. Furthermore, Kjellberg et al. [13] suggested that if the difference between $A$ and $C$-weighted values exceeds $15 \mathrm{~dB}$ then a low-frequency noise problem may exist. Then, Broner and Knight-Merz [14] method was considered in which they proposed simple criteria for the control of annoyance due to low-frequency noise. They suggested that if the noise level is fluctuating by $5 \mathrm{~dB}(\mathrm{C})$, then a penalty of $5 \mathrm{~dB}(\mathrm{C})$ should be added i.e., the criteria should be reduced. Consequently, an examination on the presence of a tone was carried out. Data on frequency spectra were used to identify the presence of a tone. The level in one $1 / 3 \mathrm{rd}$ octave band to the level in the two adjacent bands was compared according to ISO 1996-2 [15]. It was suggested that if the tone is $15 \mathrm{~dB}$ in the low-frequency one-third-octave band $(25 \mathrm{~Hz}$ to $125 \mathrm{~Hz}$ ), the annoyance might be due to low-frequency content. Then, a further procedure for the assessment of low frequency noise presented by Newman and McEwan [16] who referred a British Gas Corporation criterion for specifying noise control for gas turbines will be referred. The procedure involves a $60 \mathrm{~dB}$ limit in the $31.5 \mathrm{~Hz}$ octave band at the nearest dwelling. An additional weighting factor of $5 \mathrm{~dB}$ can be added to the average A-weighted if the limit is exceeded.

\section{Results and discussions}

\subsection{Annoyance due to change in sound levels indices}

The relationship between the $\mathrm{L}_{\text {Aeq }}$ produced with speed and MO and MLO is shown in Fig. 2 (a) and (b), respectively. The increasing trend in sound level with GVW was found to be in polynomial equation of second degree with very good relationship, where the GVW explained more than $90 \%$ of the variations. In general, both type of TRS generated higher sound level at higher speed $(50 \mathrm{~km} / \mathrm{h})$ by maximum $8 \mathrm{~dB}(\mathrm{~A})$ compared with speed $30 \mathrm{~km} / \mathrm{h}$ only by $6 \mathrm{~dB}(\mathrm{~A})$ when traversed by all tested commercial vehicles.

It can be seen that the MO, when transited by all types of commercial vehicle with speed of $50 \mathrm{~km} / \mathrm{h}$, produced increasing sound level from 1 to $2.2 \mathrm{~dB}(\mathrm{~A})$ relative to the normal road, while at the lower speed, only the 40 seated bus $(7700 \mathrm{~kg})$ yielded sound level increment of $2.9 \mathrm{~dB}(\mathrm{~A})$. On the other hand, the MLO seemed to absorb the sound level produced by the tyre and propulsion as the vehicle speed reached $50 \mathrm{~km} / \mathrm{h}$. The installation of MLO increased sound level at value of $2.4 \mathrm{~dB}(\mathrm{~A})$ only when the Hiace with GVW of $2600 \mathrm{~kg}$ at $50 \mathrm{~km} / \mathrm{h}$ traversed it and also from the one ton lorry with speed of $30 \mathrm{~km} / \mathrm{h}$ and 3 $\mathrm{dB}(\mathrm{A})$ increase in sound level. Based on the increment of sound level, only the one ton lorry which travelled at $30 \mathrm{~km} / \mathrm{h}$ produced the increment of $3 \mathrm{~dB}(\mathrm{~A})$. It is seen the corresponding increase in sound level values for with and without do not exceed 
the $5 \mathrm{~dB}(\mathrm{~A})$ [17], this indicates that there may not be a significant problem in the noise generated by both type TRS when vehicles transit on them.

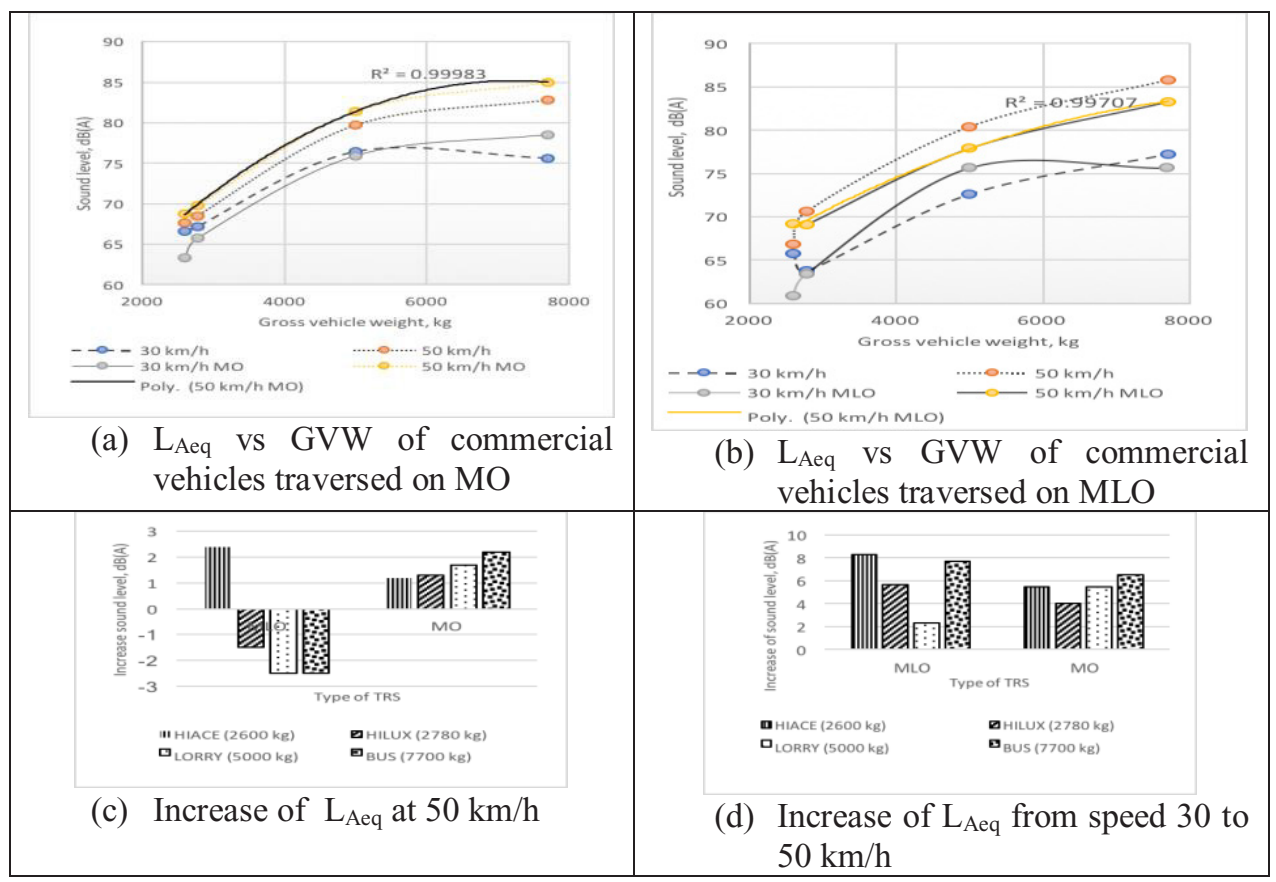

Fig. 2. Changes in sound level.

\subsubsection{Impulsive characteristics}

Fig. 3 shows the comparison of impulsive chrateristics with reference limits. According to (LAIeqT -LAeq), it was found out that all vehicles do not poses impulsive noise (Figure 3c). However, by considering (LAFmax - LAImax ), (LAFmax - LAeq ) and (LAImaxLASmax), it was founded that the MO produced significant impulsive noise when both LV and MV transited at speed of $30 \mathrm{~km} / \mathrm{h}$. The significant impulsivity was obtained when GVW $>5000 \mathrm{~kg}$ produced (LAFmax - LAImax) and (LAImax-LASmax) values greater than 10 (Fig. 3a) and $6 \mathrm{~dB}$ (Fig. 3d), respectively, while $\mathrm{GVW}<5000 \mathrm{~kg}$ yielded (LAFmax-LAeq) value greater than 10 (Fig. 3b). For MLO, only LV produced significant impulsive noise when it traversed at speed of $30 \mathrm{~km} / \mathrm{h}$ and this can be identified through (LAFmax - LAeq ) value which exceeded $10 \mathrm{~dB}$ when $\mathrm{GVW}<4000 \mathrm{~kg}$. Thus, MO and MLO will cause impulsive characteristics if the LV such as Hiace and Hilux transit on them at a lower speed. From the standpoint of annoyance, if the activity occurs at nighttime the effect would be considerably more detrimental than day-time exposure.

\subsection{Annoyance due to Low frequency noise}

\subsection{1 $d B(C)-d B(A)$}

TRS profile also affects the frequency spectrum composition of the noise emitted in low, medium, and high frequencies. Fig. 4 shows sound level spectrum, A-weighted, and Cweighted sound level generated by a bus that travelled on MO and without MO. The 
average increase in sound level in low frequency fluctuated compared to the higher frequency. Overall, the increase of total $\mathrm{dB}(\mathrm{A})$ and total $\mathrm{dB}(\mathrm{C})$ from that of without $\mathrm{MO}$ were, $1.18 \mathrm{~dB}(\mathrm{~A})$ and $1.39 \mathrm{~dB}(\mathrm{C})$, respectively. The results of the $\mathrm{dB}(\mathrm{C})-\mathrm{dB}(\mathrm{A})$ values with and without TRS at different speeds highlighted that the corresponding values did not exceed the $15 \mathrm{~dB}$ threshold as suggested by Kjellberg et al [13]. As mentioned previously, this situation indicated that there may not be a significant low-frequency problem in the noise generated by both types of TRS when the vehicles traversed them.

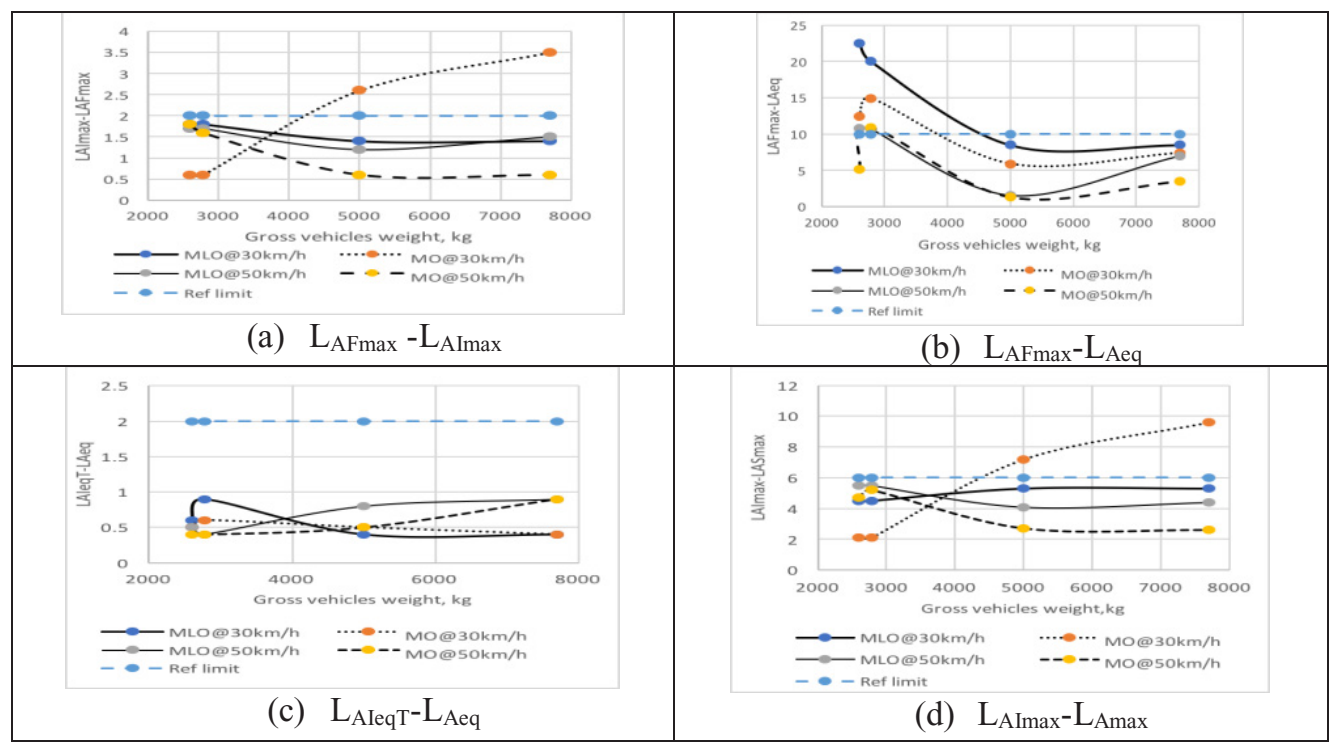

Fig. 3. Examination of impulsive characteristic.

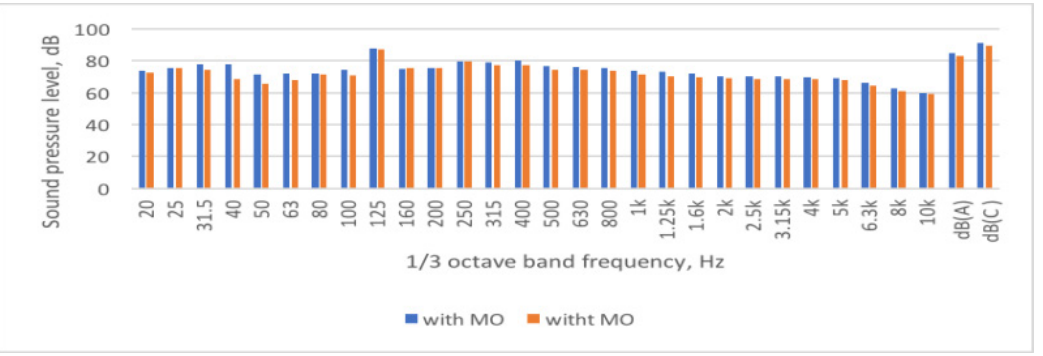

Fig. 4. Frequency spectra in $\mathrm{dB}, \mathrm{dB}(\mathrm{A})$ and $\mathrm{dB}(\mathrm{C})$ when 40 set bus traverse on TRS at speed 50 $\mathrm{km} / \mathrm{h}$.

\subsubsection{Fluctuation of $d B(C)$}

Table 2 shows the fluctuation of $\mathrm{dB}(\mathrm{C})$ between with and without TRS and speeds of $30 \mathrm{~km} / \mathrm{h}$ and $50 \mathrm{~km} / \mathrm{h}$. The noise level fluctuation was higher than $5 \mathrm{~dB}(\mathrm{C})$ when a lorry traversed the MLO, which indicated the presence of a low-frequency noise. Thus, a spectrum analysis was conducted to assess the extent of noise in the lower frequency bands, namely in the region between $20 \mathrm{~Hz}$ to $125 \mathrm{~Hz}$. 


\subsubsection{Tonal examination in $20 \mathrm{~Hz}$ to $125 \mathrm{~Hz}$}

The investigation showed that there were no significant tones that can be identified using the methodology outlined in ISO 1996-2 when LV and MV, investigated in this study, traversed the TRS. Fig. 5 shows the difference of level or tone produced between $20 \mathrm{~Hz}$ to $125 \mathrm{~Hz}$ when vehicles transit and do not transit the TRS. In general, the tone produced by the vehicles that transited on the TRS appeared to be reduced. The installation of MO reduced the annoyance from the Hiace, lorry, and bus travelling at speed of $50 \mathrm{~km} / \mathrm{h}$. Moreover, at $30 \mathrm{~km} / \mathrm{h}$, the MLO and and MO reduced the significant tone generated by the Hiace and lorry, respectively. Thus, it can be said that noise generated by the TRS produced a broadband source with a clear low-frequency content.

Table 2. Fluctuation of $\mathrm{dB}(\mathrm{C})$ with and without TRS.

\begin{tabular}{|c|c|c|c|c|}
\hline \multirow{2}{*}{$\begin{array}{c}\text { Vehicles } \\
\text { type }\end{array}$} & \multicolumn{2}{|c|}{$30 \mathrm{~km} / \mathrm{h}$} & \multicolumn{2}{c|}{$50 \mathrm{~km} / \mathrm{h}$} \\
\cline { 2 - 5 } & $\mathrm{MO} \mathrm{dB}(\mathrm{C})$ & $\mathrm{MLO} \mathrm{dB}(\mathrm{C})$ & $\mathrm{MO} \mathrm{dB}(\mathrm{C})$ & $\mathrm{MLO} \mathrm{dB}(\mathrm{C})$ \\
\hline HiAce & 0.72 & -6.98 & 4.98 & -15.04 \\
\hline Hilux & 0.92 & -4.32 & 3.67 & -14.5 \\
\hline Lorry & -2.59 & 0.09 & -5.49 & 5.59 \\
\hline Bus & 0.93 & -6.36 & 1.39 & -3.95 \\
\hline
\end{tabular}

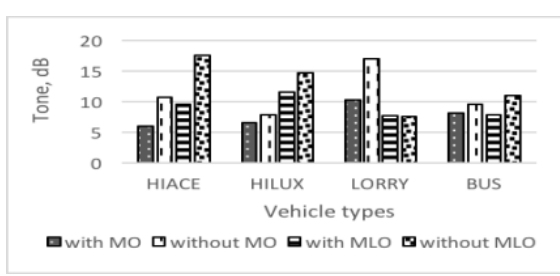

(a) speed $30 \mathrm{~km} / \mathrm{h}$

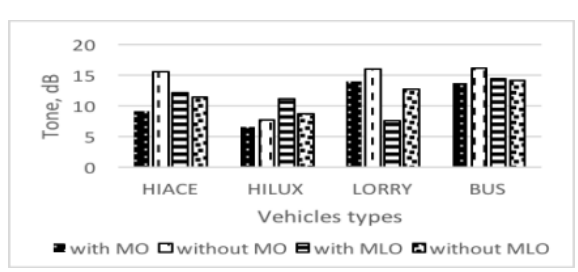

(b) speed $50 \mathrm{~km} / \mathrm{h}$

Fig. 5. Examination of tone existing between 25 to $125 \mathrm{~Hz}$ when vehicles traverse on TRS.

\subsubsection{Examination of sound level in $31.5 \mathrm{~Hz}$}

Fig. 6 shows the logarithmic addition of the $25 \mathrm{~Hz}, 31.5 \mathrm{~Hz}$, and $40 \mathrm{~Hz}$ third octave band levels comparison with the $31.5 \mathrm{~Hz}$ octave band criterion of $60 \mathrm{~dB}$ as set by British Gas Corporation [16]. It can be seen that total sound levels with the TRS was higher than that of without TRS and also the criteria were exceeded even though the MV transited and did not transit the TRS. The bus produced the highest sound levels when passing the road with MO at speeds of 30 and $50 \mathrm{~km} / \mathrm{h}$ and exceeded by $15.7 \mathrm{~dB}$ and $19.9 \mathrm{~dB}$, respectively. This indicated that a low-frequency noise was likely to be added to the overall night-time sleep disturbance and annoyance level at nearby residents. The results showed that the lowfrequency noise was significant when the MV traversed the MO and MO, an additional weighting factor of $5 \mathrm{~dB}$ can be added to the average A-weighted value during night-time. 


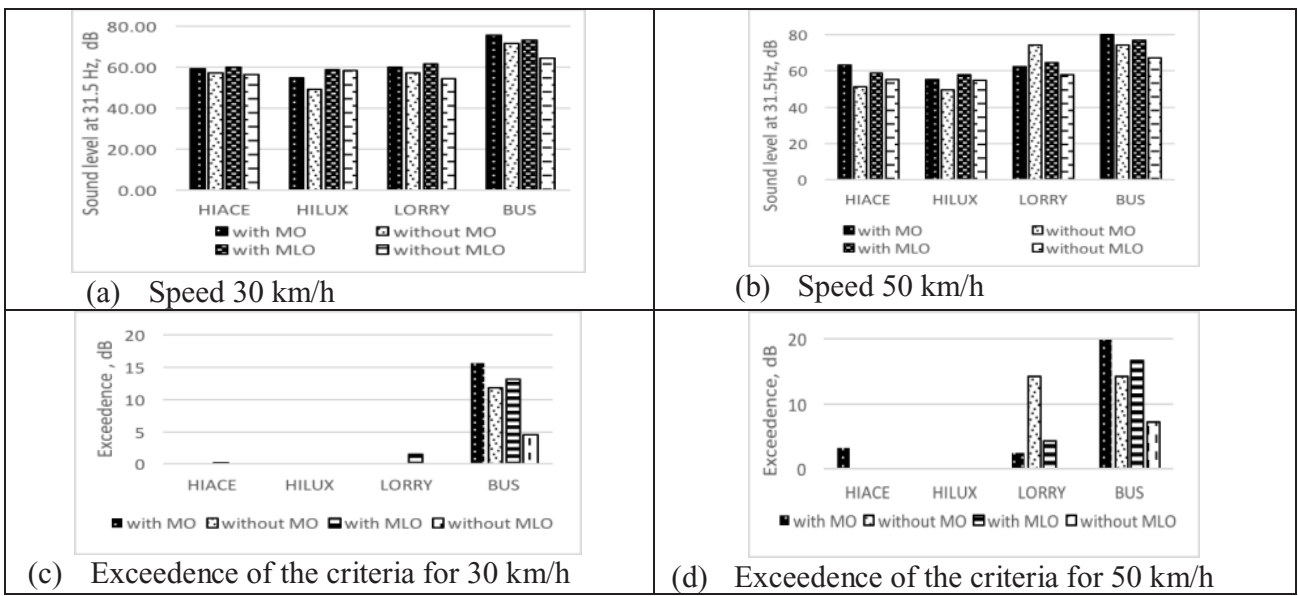

Fig. 6. Examination on sound level at $31.5 \mathrm{~Hz}$.

\section{Conclusions}

The current study investigated noise annoyance that arised due to the MO and MLO installations as they were traversed by commercial vehicles. The following conclusions were obtained:

- Both types of TRS produced higher sound level at higher speed $(50 \mathrm{~km} / \mathrm{h})$ compared to the lower speed $(30 \mathrm{~km} / \mathrm{h})$ when traversed by all commercial vehicles.

- Annoyance did not arise due to the increase of sound level as it was below the limit of $5 \mathrm{~dB}$.

- Annoyance occurred when all commercial vehicles considered in this study transited the MO with speed of $30 \mathrm{~km} / \mathrm{h}$ and only light commercial vehicles with the same speed of $30 \mathrm{~km} / \mathrm{h}$ traversed the MLO.

- Annoyance also arised due to low frequency noise that resulted when light (Hiace) and medium weight commercial vehicles (bus and lorry) traversed both MO and MLO.

- MO reduced annoyance from Hiace, lorry, and bus that travelled at $50 \mathrm{~km} / \mathrm{h}$.

\section{References}

1. Z. Haron, M.H. Othman, M. H., K. Yahya, K., M.R. Hainin, K. Ambak, \& N. Darus, MATEC Web of Conferences.(2017)

2. M. H. Othman, Z. Haron, M.R. Hainin, K. Yahya, H. Yaacob, M. E. Sanik: Jurnal Teknologi. 73 (2015)

3. M.M. Abd Manan, P.W.H, Alvin, Malaysian institute of Road Malaysian Research (2009)

4. Manual fasiliti keselamatan jalan, Cawangan Kejuruteraan Jalan dan Geoteknik, Jabatan Kerja Raya Malaysia (2014).

5. D. S. An, S.A. Kwon, J. Lee, Y.C. Suh, ASCE, J. Perf. Faci. ASCE (2016)

6. E. Murphy, E.A. King, Environment International 63 (2014)

7. K. Persson, M. Bjorkman, J Sound Vibration 127 (1988)

8. B. Berglund, T. Lindvall, D. Schwela, K.T. Goh, WHO (1999)

9. G.H. Leventhall, DEFRA (2003) 
10. M.E. Beutel, C. Jünger, E.M. Klein, P.W.K Lackner, M. Blettner, H. Binder, M. Michal, J. Wiltink, E. Brähler, T. Münzel, https://doi.org/10.1371/journal.pone.0155357(2016)

11. http://www.maa.org.my/info_summary.htm, (assessed March 2017)

12. ISO (1997a). ISO 11819-1:2001

13. Kjellberg, M. Tesarz, K. Holmberg, U. Landstrom (Environment International) 23 (1997)

14. N. Broner, S. Knight-Merz, Acoustics Australia 39 (2011)

15. ISO 1996-2 (2007) ISO 1996-2:2007

16. J.R. Newman, K.I. McEwan K. I, Journal of Engineering for Power 102 (1980)

17. J.L. Darbyshire, J.D. Young, Critical Care 17 (2013) 